shared equally between Professor Ramsay and himself. In some quarters there had been a tendency to represent that antagonism existed between chemists and physicists in the matter, though such a thought had never entered his head. Professor Ramsay was a chemist by profession, while he himself had dabbled in chemistry from an early age, and had followed its development with very keen interest."

I returned from France to Ramsay's laboratory as an assistant in the autumn of I 894 , and the first words he said to me, after shaking hands, were, "Well, it is a new gas." From April I895 I was daily associated with him for years, and I have heard the early history of the discovery told many times. This I know for a fact: when Ramsay communicated his preliminary results to Lord Rayleigh, he placed them at his disposal, but Lord Rayleigh was equally willing to allow Ramsay to go forward with the work alone. I do not believe that either of these two great men ever felt the slightest regret that the discovery was shared. As a matter of fact, if neither of them had discovered argon their reputation would be scarcely less enduring.

Even during the preliminary stage, there were attempts to disturb the friendly relations between the two discoverers. A well-known chemist called on Ramsay, and after being shown everything, after the manner of Ramsay, went home and wrote to Lord Rayleigh, telling him that he must place no reliance on Ramsay's work. Lord Rayleigh sent the letter on to Ramsay, with a brief comment, which Ramsay passed on to the author. Later the "Suum cuique" letters in the Chemical News showed chemists that there were people in their ranks capable of the most unworthy actions.

However, Ramsay, when alive, knew well when to meet and reply to criticism, and when to "Lat them say." Ramsay, dead, will not suffer from attacks directed from " behind the scenes" ; but it may be hoped that the pages of NATURE will not be open to those who would discredit him in this manner.

MORRIS W. TRAVERS.

I47 Queen Victoria Street,

London, E.C.4, January I2.

\section{The Possibility of reproducing the Electrical Conditions of the Nitrogen Afterglow.}

In a paper by Johnson and myself (Proc. Roy. Soc. A, vol. I06, p. 200) on the effect of argon on certain spectra, attention was directed to structural modifications induced in the $\mathrm{CH}$ band, $\lambda_{43} \mathrm{I}_{5}$, and in the $\mathrm{CN}$ bands, these being similar to changes observed by Strutt and Fowler (Proc. Roy. Soc. A, vol. 86, p. II6), when these spectra were stimulated in the afterglow of nitrogen. In a recent paper by Johnson (Phil. Mag. vi., vol. 48, p. 1069) further evidence has been adduced for the similarity of the electrical conditions obtained in the afterglow to those existing when mild uncondensed discharges are passed through highpressure argon. In particular, an energy displacement in the first positive band spectrum, as developed in a tube containing a little nitrogen in the presence of high-pressure argon, was regarded as the analogue of the selection of three of the more refrangible heads in the several groups constituting the visible spectrum of the afterglow. The energy displacement was related quantitatively to the percentage of nitrogen in the nitrogen-argon mixture. If the analogy can be sustained, it should follow that the intensity maximum in the several groups of the afterglow spectrum will be displaced a little towards the violet end as the afterglow is dying away (that is, as the percentage of activated molecules diminishes).
To test this, the spectrum of the afterglow has been photographed through a neutral wedge at two points about 7 inches apart in a glass tube, through which a stream of glowing nitrogen was pumped. Owing to the comparatively small light gathering power of the spectrograph, photographic exposures of 16 and 40 hours respectively were necessary, and even then the intensity was insufficient to permit of quantitative measurement of the plates. A close comparison, however, indicated no pronounced energy displacement.

Attempts have also been made to reproduce the $\beta$-group of the afterglow spectrum from discharge tubes containing nitrogen and argon, but no positive results have been obtained. Incidentally, I have examined the spectrum of the light from discharges through ammonia in high-pressure argon, in the hope of obtaining the spectrum of the afterglow when atomic nitrogen (arising from the destruction of the $\mathrm{NH}_{3}$ molecule) returned to the molecular state. There was no evidence, however, of either the characteristic $a$ or $\beta$ groups occurring.

I have also excited the band spectrum of iodine in the presence of high-pressure argon, but did not observe the relative intensity changes which Strutt and Fowler record as characteristic of the development in the afterglow.

It would appear, therefore, that while there remain several points of resemblance between the electrical conditions of the afterglow and those existing when a mild discharge is passed through high-pressure argon, there are many specific effects of the former which are incapable of reproduction in the latter case.

The Queen's University, Belfast, W. H. B. Cameron. December 22, I924.

\section{Science and the Community.}

THE article under this title in the issue of NATURE of January 3 refers to the small part played by scientific men in public affairs and in business life. I think that the explanation of this is simple. One man has a fixed amount of daily energy. If he makes a great effort in one direction his effort in another direction is correspondingly weak; and so, in general, one man cannot excel in more than one direction.

Now a successful business man, or, even more so, a politician, owes his success almost entirely to his powers of divining the wishes and thoughts of that strange creature-man. A man of science, however, is dealing with an inanimate world which cannot be influenced by tact, persuasive powers, or individuality. Consequently, in general, those personal qualities and mental characteristics which lead a man to success in business have no relationship at all to those which lead to success in scientific work. In fact, the inexactitudes and tactful misrepresentations characteristic of the business and political world are excessively distasteful to a man trained in the clear honesty and rigour of scientific thought, and put him at a positive disadvantage compared to his commercial fellow-man when engaged upon delicate negotiations of any sort.

In general, a man who has worked for years studying physics and higher mathematics will be much less tactful and much less persuasive, and will probably be a worse judge of character, than a man who has spent an equally strenuous number of years in persuading people to buy something which they do not really need.

Rosherville Court, Burch Road, GEOFFrEY Martin.

Gravesend, January 5. 